\title{
THE NATURE OF THE INHERITANCE OF PERMANENTLY INDUCED CHANGES IN NICOTIANA RUSTICA
}

\author{
II. $F_{4}$ AND $F_{5}$ GENERATIONS OF SELECTED CROSSES
}

\author{
EVELYN G. EGLINGTON and CAROL A. MOORE \\ Department of Genetics, University of Birmingham, Birmingham B15 2TT, England
}

Received 1.viii.72

\begin{abstract}
Summary
The $\mathbf{F}_{4}$ and $\mathbf{F}_{5}$ generations of the two selected crosses, $n k_{2} \times n i l_{1}$ and $p_{3} \times n i l_{3}$, from a dialle of all possible crosses between the three conditioned lines $p$, nil and $n k$ were grown in successive years in the summers of 1970 and 1971 respectively in order to study (1) the persistence of the segregation between $F_{I}$ individuals seen in earlier generations and (2) the conventional segregation in the later generations. In the $\mathrm{F}_{4}$ generation $\mathrm{F}_{1}$ segregation in the cross $n k_{2} \times n i l_{1}$ approaches significance for the character final height. In the $\mathbf{F}_{5}$ generation significant segregation between $\mathbf{F}_{\mathbf{1}}$ individuals was not found for the characters final height and flowering time for either cross. However, in the cross $n k_{2} \times n i l_{1}$ significant $F_{1}$ segregation was found for two other characters, height at flowering time and the diameter of the eighth leaf. The presence of segregation at the $F_{2}, F_{3}$ and $F_{4}$ levels was confirmed for both characters in both crosses by the fitting of a standard additive genetical and additive environmental model. From the estimates of $D$ obtained the numbers of effective factors by which these lines differ were found to range from three to five.
\end{abstract}

\section{INTRODUCTION}

Previous investigation (Perkins, Eglington and Jinks, 1971) of all possible crosses between three differently conditioned lines derived from purebreeding variety 16 of Nicotiana rustica have established that $F_{1}$ individuals of the same cross differ for final height and flowering time and that these differences persist into the $\mathrm{F}_{2}$ progenies of all crosses and the $\mathrm{F}_{3}$ 's of some of them. Furthermore, segregation in the $\mathrm{F}_{2}$ and $\mathrm{F}_{3}$ generations of these crosses appeared to be of the conventional kind that is observed in the same generations when derived from a cross between different inbred genotypes. In both respects the behaviour of the conditioned lines of $\mathcal{N}$. rustica resembles that of similarly conditioned lines of flax (Durrant and Tyson, 1964). Two crosses, $p_{3} \times n i l_{3}$ and $n k_{2} \times n i l_{1}$, chosen because they provide the clearest evidence of differences among $F_{1}$ individuals which persisted to their corresponding $\mathrm{F}_{2}$ 's, have been chosen to provide $\mathrm{F}_{4}$ and $\mathrm{F}_{5}$ families. These were grown in the summers of 1970 and 1971 respectively, in order to study further the persistence of the $F_{1}$ segregation and the conventional segregations in the later generations.

\section{Experimental materials}

The $\mathrm{F}_{4}$ and $\mathrm{F}_{5}$ families were obtained by repeated selfing from the two crosses $p_{3} \times n i l_{3}$ and $n k_{2} \times n i l_{1}$ (Perkins, Eglington and Jinks, 1971).

Twenty $\mathrm{F}_{4}$ families of each cross were grown in 1970 , these families can be divided according to their ancestry into (1) five $F_{1}$ groups, (2) two $F_{2}$ 
TABLE 1

Analyses of variance of family means for the $F_{4}$ and $F_{5}$ generations of the $p_{3} \times$ nil $l_{3}$ and $n k_{2} \times n i l_{1}$ crosses, for the character final height, measured in centimetres

Item

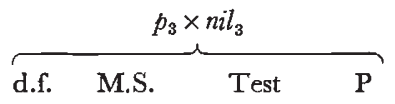

$\overbrace{\text { d.f. M.S. } \quad n k_{2} \times n i l_{1}}^{\text {Test } \quad \text { P }}$

(a) $F_{4}$ generation

1. $\mathrm{F}_{1}$ groups $\left(\mathrm{F}_{1}\right)$

2. $\mathrm{F}_{2}$ groups in $\mathrm{F}_{1}\left(\mathrm{~F}_{2}\right)$

3. $F_{3}$ groups in $F_{2}\left(F_{3}\right)$

4. Blocks (B)

5. $\mathrm{B} \times \mathrm{F}_{1}$

6. $\mathrm{B} \times \mathrm{F}_{2}$

7. $\mathrm{B} \times \mathrm{F}_{3}$

8. Replicates

$\begin{array}{rr}4 & 71 \cdot 04 \\ 4 & 277 \cdot 56 \\ 9 & 36 \cdot 60 \\ 1 & 0 \cdot 34 \\ 4 & 4 \cdot 60 \\ 4 & 2 \cdot 80 \\ 9 & 21 \cdot 40 \\ 324 & 11 \cdot 43\end{array}$

$\begin{array}{cc}\text { V.R. (2) } & \text { n.s. } \\ \text { V.R. (7) } & * * \\ \chi^{2}(8) & * * * \\ \chi^{2}(8) & \text { n.s. } \\ \chi^{2}(8) & \text { n.s. } \\ \chi^{2}(8) & \text { n.s. } \\ \chi^{2}(8) & \text { n.s. }\end{array}$

$\begin{array}{rrcc}4 & 157 \cdot 30 & - & \dagger \\ 5 & 44 \cdot 17 & \text { V.R. (3) } & \text { n.s. } \\ 10 & 52 \cdot 68 & \chi^{2}(8) & * * * \\ 1 & 43 \cdot 89 & \text { V.R. }(5) & \text { n.s. } \\ 4 & 37.92 & \chi^{2}(8) & * \\ 5 & 12 \cdot 91 & \chi^{2}(8) & \text { n.s. } \\ 10 & 15 \cdot 28 & \chi^{2}(8) & \text { n.s. } \\ 360 & 14.27 & & \end{array}$

(b) $F_{5}$ generation
1. $\mathrm{F}_{1}$ groups $\left(\mathrm{F}_{1}\right)$
2. $\mathrm{F}_{2}$ groups in $\mathrm{F}_{1}\left(\mathrm{~F}_{2}\right)$
3. $\mathrm{F}_{3}$ groups in $\mathrm{F}_{2}\left(\mathrm{~F}_{3}\right)$
4. $\mathrm{F}_{4}$ groups in $\mathrm{F}_{3}\left(\mathrm{~F}_{4}\right)$
5. Blocks (B)
6. $\mathrm{B} \times \mathrm{F}_{1}$
7. $\mathrm{B} \times \mathrm{F}_{2}$
8. $\mathrm{B} \times \mathrm{F}_{3}$
9. $\mathrm{B} \times \mathrm{F}_{4}$
10. Replicates

$\begin{array}{rrlc}4 & 97.68 & \text { V.R. (2) } & \text { n.s. } \\ 4 & 402 \cdot 11 & \text { V.R. (4) } & * * \\ 9 & 83.53 & \text { V.R. (4) } & \text { n.s. } \\ 18 & 35.68 & \text { V.R. (9) } & * \\ 1 & 539.81 & \text { V.R. (9) } & * * * \\ 4 & 9 \cdot 35 & \text { V.R. (9) } & \text { n.s. } \\ 4 & 7.08 & \text { V.R. (9) } & \text { n.s. } \\ 9 & 8 \cdot 14 & \text { V.R. (9) } & \text { n.s. } \\ 18 & 12 \cdot 13 & \chi^{2}(10) & * \\ 592 & 7 \cdot 49 & & \end{array}$

$\begin{array}{rrlc}4 & 311.82 & \text { V.R. (3) } & \text { n.s. } \\ 5 & 156.55 & \text { V.R. (3) } & \text { n.s. } \\ 10 & 89 \cdot 82 & \text { V.R. (4) } & * * \\ 20 & 19.96 & \chi^{2}(10) & * \\ 1 & 928.32 & \chi^{2}(10) & * * * \\ 4 & 11 \cdot 61 & \chi^{2}(10) & \text { n.s. } \\ 5 & 12 \cdot 32 & \chi^{2}(10) & \text { n.s. } \\ 10 & 12 \cdot 20 & \chi^{2}(10) & \text { n.s. } \\ 20 & 9.07 & \chi^{2}(10) & \text { n.s. } \\ 698 & 11 \cdot 66 & & \end{array}$

$\dagger$ No real test of significance is available as both Items 3 and 5 are significant. n.s. Probability is non-significant. * Probability $=0.01-0.05 ; * *$ Probability $=0.001-0.01 ; * * *$ Probability $<0.001$.

TABLE 2

Analyses of variance of family means for the $F_{4}$ and $F_{5}$ generations of the $p_{3} \times n i l_{3}$ and $n k_{2} \times n i l_{1}$ crosses, for the character flowering time

\section{Item}

(a) $F_{4}$ generation
1. $F_{1}$ groups $\left(F_{1}\right)$
2. $\mathrm{F}_{2}$ groups in $\mathrm{F}_{1}\left(\mathrm{~F}_{2}\right)$
3. $\mathrm{F}_{3}$ groups in $\mathrm{F}_{2}\left(\mathrm{~F}_{3}\right)$
4. Blocks (B)
5. $\mathrm{B} \times \mathrm{F}_{1}$
6. $\mathrm{B} \times \mathrm{F}_{2}$
7. $\mathrm{B} \times \mathrm{F}_{3}$
8. Replicates

(b) $F_{5}$ generation

1. $\mathrm{F}_{1}$ groups $\left(\mathrm{F}_{1}\right)$

2. $F_{2}$ groups in $F_{1}\left(F_{2}\right)$

3. $\mathrm{F}_{3}$ groups in $\mathrm{F}_{2}\left(\mathrm{~F}_{3}\right)$

4. $\mathrm{F}_{4}$ groups in $\mathrm{F}_{3}\left(\mathrm{~F}_{4}\right)$

5. Blocks (B)

6. $\mathrm{B} \times \mathrm{F}_{1}$

7. $\mathrm{B} \times \mathrm{F}_{2}$

8. $\mathrm{B} \times \mathrm{F}_{3}$

9. $\mathrm{B} \times \mathrm{F}_{4}$

10. Replicates

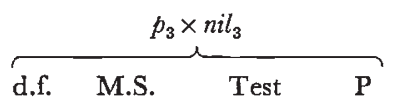

$\begin{array}{rr}4 & 16 \cdot 70 \\ 4 & 46 \cdot 10 \\ 9 & 2 \cdot 20 \\ 1 & 0 \cdot 15 \\ 4 & 0 \cdot 34 \\ 4 & 0 \cdot 31 \\ 9 & 0 \cdot 82 \\ 324 & 0 \cdot 88\end{array}$

$\begin{array}{ll}\text { V.R. (2) } & \text { n.s. } \\ \text { V.R. }(3) & * * \\ \chi^{2}(8) & * * * \\ \chi^{2}(8) & \text { n.s. } \\ \chi^{2}(8) & \text { n.s. } \\ \chi^{2}(8) & \text { n.s. } \\ \chi^{2}(8) & \text { n.s. }\end{array}$

$\begin{array}{rr}4 & 17 \cdot 82 \\ 4 & 53 \cdot 22 \\ 9 & 11 \cdot 64 \\ 18 & 2 \cdot 63 \\ 1 & 3 \cdot 32 \\ 4 & 0 \cdot 32 \\ 4 & 0 \cdot 51 \\ 9 & 0 \cdot 30 \\ 18 & 0 \cdot 69 \\ 602 & 0 \cdot 45\end{array}$

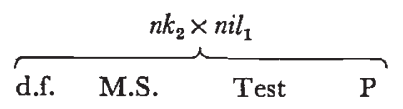

$\begin{array}{rrcc}4 & 19 \cdot 55 & \text { V.R. (2) } & \text { n.s. } \\ 5 & 17.51 & \text { V.R. (7) } & * * * * \\ 10 & 4 \cdot 43 & \text { V.R. (7) } & \text { n.s. } \\ 1 & 0.55 & \text { V.R. (7) } & \text { n.s. } \\ 4 & 0 \cdot 43 & \text { V.R. (7) } & \text { n.s. } \\ 5 & 1 \cdot 46 & \text { V.R. (7) } & \text { n.s. } \\ 10 & 1.78 & \chi^{2}(8) & * \\ 360 & 0.82 & & \end{array}$

Symbols as in table 1 . 
groups within each $F_{1}$ group, (3) two $F_{3}$ groups ( $=F_{4}$ families) within each $\mathrm{F}_{2}$ group. Similarly, $40 \mathrm{~F}_{5}$ families were grown in 1971 which can be divided into the same groups with an additional division, (4) two $\mathrm{F}_{4}$ groups ( $=\mathrm{F}_{5}$ families) within each $\mathrm{F}_{3}$ group (tables 1 and 2), each group being descended from a single selfed plant in the generation specified. Each family consisted of 10 individually randomised plants in each of two replicate blocks.

In the cross $p_{3} \times n i l_{3}$ the entire data for one $F_{2}$ group, comprising two $F_{3}$ groups in the $F_{4}$ and four $F_{4}$ groups in the $F_{5}$ generation, has been removed from all analyses for reasons discussed by Perkins, Eglington and Jinks (1971).

\section{RESULTS}

\section{(B) $F_{1}$ segregation}

The analyses of variance are given for each cross and generation separately in table 1 for final height and in table 2 for flowering time. These analyses have the same structure as those presented on p. 450 of the previous paper (Perkins, Eglington and Jinks, 1971) but are extended to include the $F_{4}$ and $F_{5}$ generations.

In no case is there significant evidence of segregation between $F_{1}$ groups although for both generations and characters of the $n k_{2} \times n i l_{1}$ cross the relevant mean square is the largest main effect apart from that between blocks. In the $\mathrm{F}_{4}$ generation of the cross $n k_{2} \times n i l_{1}$ for the character final height (table 1) there is no test for Item 1 owing to the significance of both its interaction with blocks (Item 5) and Item 3 (between $F_{3}$ groups within $\mathrm{F}_{2}$ groups). However, by calculating either $4 \sigma_{b 1}^{2}$ or $2 \sigma_{3}^{2}$ and subtracting from the empirical mean square for Item 1, it is possible to obtain an estimate of the "mean square" for differences between $F_{1}$ groups in order to test its significance. Either adjustment provides a derived mean square which is, however, still non-significant against the original error items.

\section{(B) $F_{2}, F_{3}, F_{4}$ segregation}

It can be seen from tables 1 and 2 that there is evidence that segregation is occurring at the $F_{2}, F_{3}$ and $F_{4}$ levels for both final height and flowering time in both crosses although all the relevant mean squares (Items 2 and 3 in the $F_{4}$ and 2, 3 and 4 in the $F_{5}$ generations) are not necessarily significant in each case.

To investigate the nature of the variation in the $F_{5}$ generation that occurred from the $\mathrm{F}_{2}$ generation onwards, the four rank variances, $V 2 F_{c} 5$, $V 3 F_{c} 5, V 4 F_{c} 5$ and $V 5 F_{c} 5$, which measure the mean variation ascribable to differences between $F_{2}$ great grandparents, $F_{3}$ grandparents, $F_{4}$ parents and $F_{5}$ progenies within $F_{4}$ groups, respectively, have been calculated from the analysis of variance for each of the eight combinations of characters, crosses and blocks (table 3 ). These have been equated to the standard biometrical genetical expectations in terms of a model with an additive $(D)$, dominance $(H)$ and additive environmental $\left(E_{1}\right)$ component of variation which assumes Mendelian autosomal inheritance, independence of the genes in action and in distribution and no genotype-environmental interactions. This model was found to be satisfactory in all cases when fitted by least squares precedures (Mather and Jinks, 1971) but in no case was the estimate of $H$ 
TABLE 3

Rank variances for $F_{5}$ generation of crosses $p_{3} \times n i l_{3}$ and $n k_{2} \times n i l_{1}$ grown in 1971

\begin{tabular}{|c|c|c|c|c|}
\hline Cross $p_{3} \times n i l_{3}$ & $V 2 F_{c} 5$ & $V 3 F_{c} 5$ & $V 4 F_{c} 5$ & $V 5 F_{c} 5$ \\
\hline \multicolumn{5}{|l|}{ Final height } \\
\hline Block 1 & $42 \cdot 5713$ & $15 \cdot 4820$ & $21 \cdot 9608$ & $69 \cdot 9173$ \\
\hline Block 2 & $59 \cdot 6687$ & $30 \cdot 4096$ & $25 \cdot 8501$ & $79 \cdot 0203$ \\
\hline Blocks $1+2$ & $102 \cdot 2400$ & $45 \cdot 8916$ & $47 \cdot 8109$ & $148 \cdot 9376$ \\
\hline \multicolumn{5}{|l|}{ Flowering time } \\
\hline Block 1 & $6 \cdot 7549$ & $2 \cdot 5760$ & $1 \cdot 5708$ & $4 \cdot 0244$ \\
\hline Block 2 & $6 \cdot 6792$ & $3 \cdot 3957$ & $1-7468$ & 4.9928 \\
\hline Blocks $1+2$ & $13 \cdot 4341$ & 5.9717 & $3-3176$ & $9 \cdot 0172$ \\
\hline \multicolumn{5}{|l|}{ Cross $n k_{2} \times n i l_{1}$} \\
\hline \multicolumn{5}{|l|}{ Final height } \\
\hline Block 1 & $28 \cdot 3941$ & $30 \cdot 5101$ & $13 \cdot 8785$ & $105 \cdot 1270$ \\
\hline Block 2 & $13 \cdot 8219$ & $20 \cdot 4993$ & $15 \cdot 1550$ & $128 \cdot 4373$ \\
\hline Blocks $1+2$ & $42 \cdot 2160$ & $51 \cdot 0094$ & $29 \cdot 0335$ & $233 \cdot 5503$ \\
\hline \multicolumn{5}{|l|}{ Flowering time } \\
\hline Block 1 & 0.8153 & $2 \cdot 0534$ & 0.7672 & $2 \cdot 3928$ \\
\hline Block 2 & $2 \cdot 1744$ & $2 \cdot 0757$ & $1 \cdot 1741$ & $3 \cdot 0457$ \\
\hline Blocks $1+2$ & 2.9897 & $4 \cdot 1291$ & $1 \cdot 9413$ & $5 \cdot 4385$ \\
\hline
\end{tabular}

significantly different from zero. A model was therefore refitted which omitted $H$. The analyses of goodness of fit of this model are presented in table 4. The significance of the following items are given, the joint regression over blocks, the residual variation (not accounted for by the model), the heterogeneity of the regression over the two blocks and the remainder. For flowering time the model still fits, the only significant item being the joint regression. The least-squares estimates of the parameters for flowering

TABLE 4

Analysis of variance to test the fit of the $D$ and $E_{1}$ model to data from the $F_{5}$ generation of the crosses $p_{3} \times n i l_{3}$ and $n k_{2} \times$ nil $l_{1}$ grown in 1971

Final Height

\begin{tabular}{|c|c|c|c|c|c|c|c|c|}
\hline \multirow[b]{2}{*}{ Item } & \multicolumn{4}{|c|}{$p_{3} \times n i l_{3}$} & \multicolumn{4}{|c|}{$n k_{2} \times n i l_{1}$} \\
\hline & d.f. & M.S. & Test & $\mathbf{P}$ & d.f. & M.S. & Test & $\mathbf{p}$ \\
\hline $\begin{array}{l}\text { Joint regres- } \\
\text { sion }\end{array}$ & 2 & $9137 \cdot 6443$ & V.R. (AMS) & $* * *$ & 2 & $14876 \cdot 5100$ & V.R. (AMS) & $* * *$ \\
\hline $\begin{array}{l}\text { Residual } \\
\text { Heterogeneity }\end{array}$ & 2 & $119 \cdot 1875$ & V.R. (3) & n.s. & 2 & $66 \cdot 6722$ & V.R. (3) & n.s. \\
\hline $\begin{array}{l}\text { of regression } \\
\text { Remainder }\end{array}$ & $\begin{array}{l}2 \\
2\end{array}$ & $\begin{array}{r}148 \cdot 7945 \\
4 \cdot 4970\end{array}$ & V.R. (4) & * & $\begin{array}{l}2 \\
2\end{array}$ & $\begin{array}{r}212 \cdot 3597 \\
2 \cdot 2009\end{array}$ & V.R. (4) & $* *$ \\
\hline
\end{tabular}

Flowering time

$\begin{array}{llrlllrll}\text { 1. Joint regres- } & & & & & & \\ \quad \text { sion } & 2 & 76.3384 & \text { V.R. (AMS) } & * * * & 2 & 13.7938 & \text { V.R. (AMS) } & * * * \\ \begin{array}{l}\text { 2. Residual } \\ \text { 3. Heterogeneity }\end{array} & 2 & 0.7748 & \text { V.R. (4) } & \text { n.s. } & 2 & 1.0403 & \text { V.R. (4) } & \text { n.s. } \\ \quad \begin{array}{l}\text { of regression } \\ \text { 4. Remainder }\end{array} & 2 & 0.2823 & \text { V.R. (4) } & \text { n.s. } & 2 & 0.5582 & \text { V.R. (4) } & \text { n.s. } \\ \text { 4. } & 0.1294 & & & 2 & 1 \cdot 1194 & & \end{array}$

AMS $=$ Average mean square. Symbols as in table 1. 
time have been tested (table 5) against errors determined in the usual way from the pooled mean squares of the error items (Items 2, 3 and 4 of table 4). Both $D$ and $E_{1}$ are significant in both crosses.

For final height the refitted model shows a highly significant joint regression but also a significant heterogenity between blocks. The latter item was also large for the three parameter model but non-significant due to the small number of degrees of freedom available for the test. The residual is also large, indicating the presence of some other unfitted parameter, possibly $H$, but it is not signficant against the block heterogeneity. The parameters have been tested against an error derived from the pooled mean square of Items 2 and 3 in table 4. $D$ was found to be significant for the $p_{3} \times n i l_{3}$ cross, but not for $n k_{2} \times n i l_{1}$. $\mathrm{E}_{1}$ was again significant in both crosses.

TABLE 5

Estimates of the parameters $D$ and $E_{1}$ in the $F_{5}$ generation

\begin{tabular}{|c|c|c|c|c|}
\hline \multirow[b]{2}{*}{$p_{3} \times n i l_{3}$} & & \multicolumn{3}{|c|}{ Block } \\
\hline & & 1 & 2 & 1 and 2 combined \\
\hline Final Height & $\begin{array}{l}D \\
E_{1}\end{array}$ & $\begin{array}{l}56 \cdot 4584^{*} \\
66 \cdot 8093\end{array}$ & $\begin{array}{l}85 \cdot 1967 * \\
74 \cdot 1889 *\end{array}$ & $\begin{array}{l}70 \cdot 8275^{*} \\
70 \cdot 4992 *\end{array}$ \\
\hline Flowering time & $\begin{array}{l}D \\
E_{1}\end{array}$ & $\begin{array}{l}9 \cdot 2095 * * * \\
3 \cdot 4123 * *\end{array}$ & $\begin{array}{l}9 \cdot 6053 * * * \\
4 \cdot 3807 * * *\end{array}$ & $\begin{array}{l}9 \cdot 4075 * * * \\
3 \cdot 8966 * * *\end{array}$ \\
\hline$n k_{2} \times n i l_{1}$ & & & & \\
\hline Final height & $\begin{array}{l}D \\
E_{1}\end{array}$ & $\begin{array}{l}45 \cdot 6582 \text { n.s. } \\
102 \cdot 3259 * *\end{array}$ & $\begin{array}{l}21 \cdot 3365 \text { n.s. } \\
127 \cdot 2848 * *\end{array}$ & $\begin{array}{l}33 \cdot 4974 \text { n.s. } \\
114 \cdot 8054 * *\end{array}$ \\
\hline Flowering time & $\begin{array}{l}D \\
E_{1}\end{array}$ & $\begin{array}{l}2 \cdot 1876^{*} \\
2 \cdot 3194 * *\end{array}$ & $\begin{array}{l}3 \cdot 7557 * * \\
2 \cdot 8670 * *\end{array}$ & $\begin{array}{l}2 \cdot 9717 * * \\
2 \cdot 5932 * *\end{array}$ \\
\hline
\end{tabular}

\section{(iii) The number of effective factors}

The values of $D$ from the two parameter model for the two crosses and characters were used to obtain estimates of the numbers of effective factors by which the parental lines used in the crosses differed. The formula used to estimate the numbers of effective factors was

$$
k=\frac{\left(\frac{1}{2} \text { range }\right)^{2}}{D}
$$

where $k$ is the number of effective factors and "range" is the difference between the greatest and smallest family mean among the families within each cross of the $F_{5}$ generation (averaging over blocks for flowering time, but treating blocks separately for final height in the $p_{3} \times n i l_{3}$ cross where there was heterogeneity between blocks). There is of course no estimate of the number of effective factors by which $n k$ and nil differ for final height as $D$ was non-significant. For the purpose of this estimation the $\mathbf{F}_{5}$ families are being treated as pure-breeding lines.

The estimated number of genes, to the nearest whole number, for the cases where $D$ was significant, are $p_{3} \times n i l_{3}$, final height, 3 , flowering time, 3 , and $n k_{2} \times n i l_{1}$, flowering time, 5 . These are of course minimal estimates for the usual reasons (Mather and Jinks, 1971). The distribution of the family means, averaged over blocks, in the $F_{5}$ generation is given in histogram form in figs. $l a$ and $1 b$ for final height and in figs. $2 a$ and $2 b$ for flowering time 

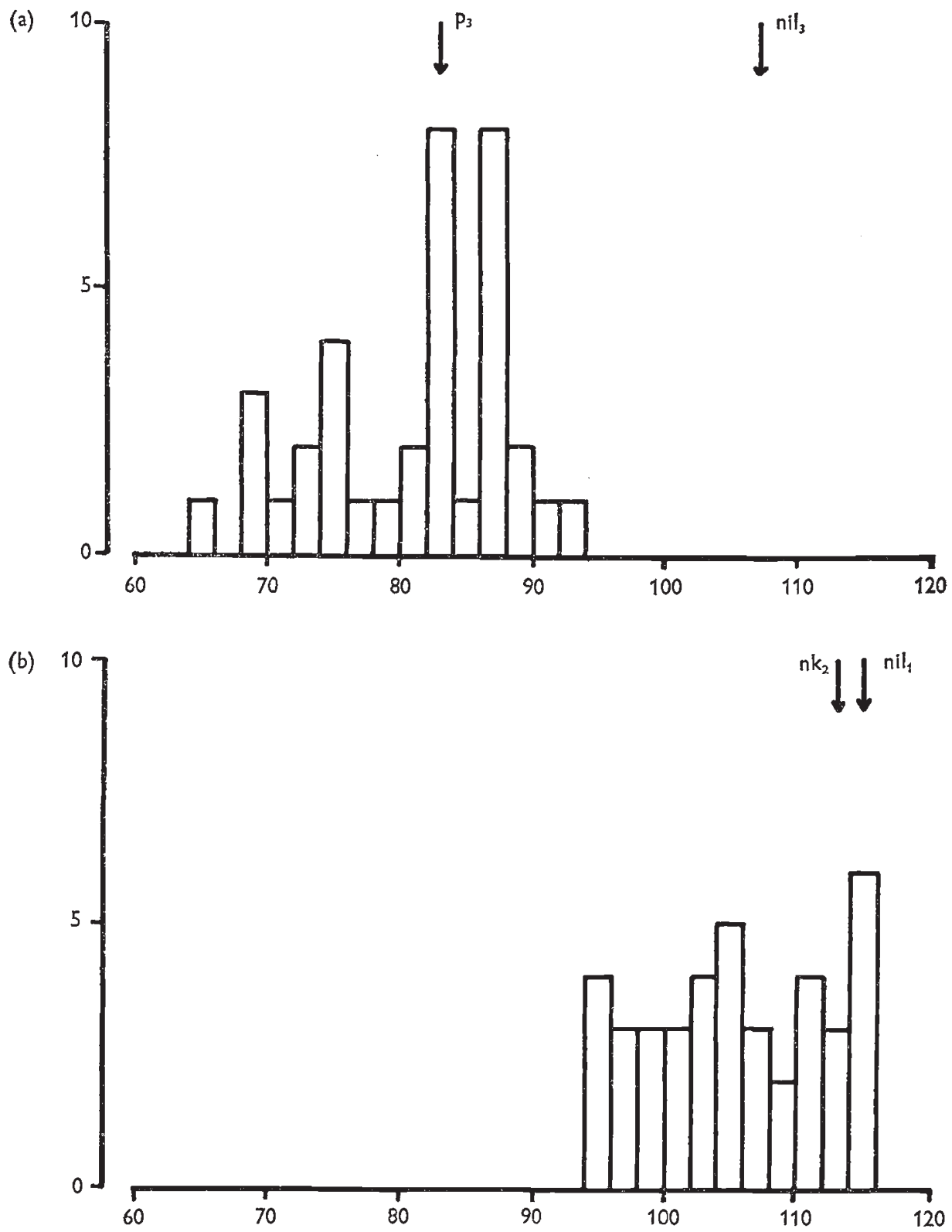

FIG. 1.- Histograms to show the distribution of the $F_{5}$ family means for the character final height for (a) the 36 families of the cross $p_{3} \times n i l_{3}$ and $(b)$ the 40 families of the cross $n k_{2} \times n i l_{1}$.

in the $p_{3} \times n i l_{3}$ and $n k_{2} \times n i l_{1}$ crosses respectively. The mean parental line values are indicated in each diagram (these parental values were obtained from an experiment adjacent to the experiment under consideration and sown on the same day, ensuring maximum similarity between the conditions experienced by the two experiments). 

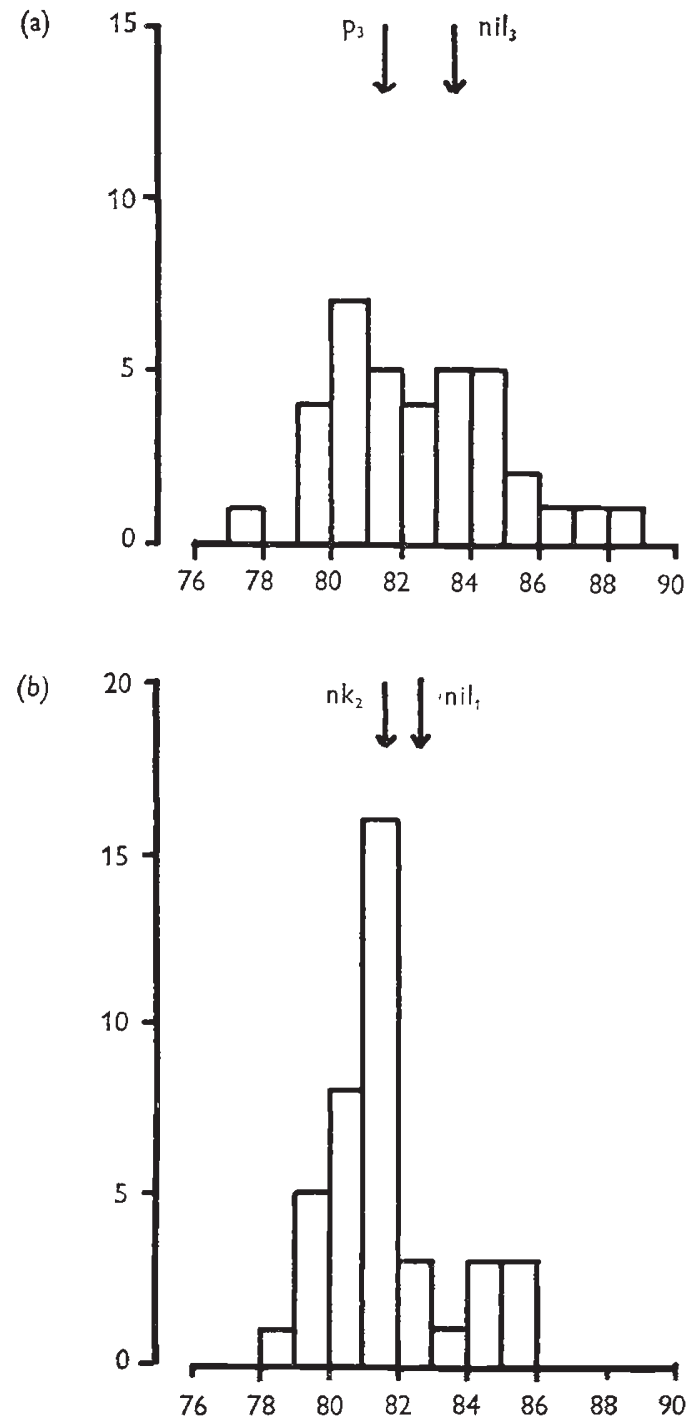

FIG. 2.-Histograms to show the distribution of the $F_{5}$ family means for the character flowering time for (a) the 36 families of the cross $p_{3} \times n i l_{3}$ and $(b)$ the 40 families of the cross $n k_{2} \times n i l_{1}$.

The range of family means for final height is similar between parents and offspring in the $p_{3} \times n i l_{3}$ cross and much larger for the offspring than the parents in the $n k_{2} \times n i l_{1}$ cross, suggesting association of genes controlling height in the former and dispersion in the latter. For flowering time both crosses have a larger range of $F_{5}$ family means than of parental values, from which it is concluded that the genes controlling flowering time are in dispersion in both crosses. However, the $n k_{2}$ and $n l_{1}$ parents show very similar flowering times in the 1971 data which may reflect the change in flowering time of some of the original standard conditioned lines in the first few generations after conditioning (Perkins, Eglington and Jinks, 1971) and changes in the environmental conditions. 


\section{Conclusions}

For neither character could the segregation which occurred in the $F_{1}$, and which could still be detected between $F_{1}$ groups in the $F_{2}$ and $F_{3}$ generations, be detected in the $\mathrm{F}_{4}$ and $\mathrm{F}_{5}$ generations of the crosses $p_{3} \times$ nil $_{3}$ and $n k_{2} \times n i l_{1}$ although in the latter cross the mean square between $F_{1}$ groups was the largest item, apart from blocks. However, part of the failure to find significant $F_{1}$ segregation must be attributable to the reduction in the number of degrees of freedom available for this item in the $F_{4}$ and $F_{5}$ data compared with earlier generations. This resulted from a reduction in the number of $F_{1}$ groups represented in the later generations because of the rapid expansion in the size of the experiment that follows from a hierarchial breeding design. The same argument applies to the alternative method of detecting the persistence of the $F_{1}$ segregation by comparing the means of $\mathrm{F}_{1}$ groups over successive generations. Using correlations to make these comparisons, the coefficients were 0.87 and 0.79 for final height and 0.73 and 0.87 for flowering time in the two crosses between the $\mathrm{F}_{3}$ and $\mathrm{F}_{4}$ generations and $0.52,0.86,0.75$ and 0.79 for the corresponding comparisons between the $F_{4}$ and $F_{5}$ generations. These are all relatively high values considering that they are comparisons over both generations and seasons, but because of the small number of $\mathrm{F}_{1}$ groups represented in these generations, none is significant, only three degrees of freedom being available for each coefficient. There are, therefore, some indications that the segregation observed in the $F_{1}$ of these crosses is still leading to differences between $F_{1}$ groups in these later generations and this is strongly supported by significant differences $(P=0.01-0.05)$ between $F_{1}$ groups in the $F_{5}$ generation for two other characters, height at flowering time and width of the eighth leaf (Eglington and Moore, unpublished).

That a biometrical genetical model consisting of additive genetical and additive environmental effects only, adequately describes the variation from the $\mathrm{F}_{2}$ generation onwards, leaves no reason to doubt that this segregation is of the conventional kind. This confirms the earlier analysis of $3 \times 3$ diallel sets of crosses in respect of the additive genetical component but not for the smaller non-additive component. This failure to detect a non-additive component is not surprising since the selfing series is relatively insensitive to the effects of non-additive variation and hence is unlikely to detect a small component of this kind.

The minimal number of effective factors detected in the crosses between the conditioned lines are of the same order of magnitude as those detected by comparable methods in crosses between conventionally derived inbred lines for the same characters (Eaves and Brumpton, 1972). That more than one and possibly many effective factors are involved in the differences between lines which have received different conditioning treatments is further supported by:

(i) the distributions of the $F_{5}$ family means for the two characters which are given in figs. 1 and 2 ;

(ii) the occurrence of families in the $\mathrm{F}_{5}$ whose means fall well outside of the parental range;

(iii) the independence or low correlations between the differences in final height and flowering time among the $\mathrm{F}_{5}$ families $(r=0.40$ and $0 \cdot 16$ for the $p_{3} \times n i l_{3}$ and $n k_{2} \times n i l_{1}$ crosses, respectively); and 
(iv) the many other characters for which there is significant variation among the $F_{5}$ families which is partly or wholly independent of final height and flowering time (Moore and Eglington, 1973). For the present, therefore, we must proceed on the assumption that sites on may chromosomes have undergone heritable changes as a result of the conditioning treatments.

Acknowledgments.-This work was carried out while one of us (Evelyn G. Eglington) was supported by a research studentship awarded by the Ministry of Agriculture, Fisheries and Food. We would like to thank Dr J. M. Perkins and Professor J. L. Jinks for much helpful comment and guidance.

\section{REFERENCES}

DURRANT, A., AND tYSON, H. 1964. A diallel cross of genotypes and genotrophs of Linum. Heredity, 29, 207-227.

EAVES, L. J., AND BRUMPTON, R. J. 1972. Factors of covariation in Nicotiana rustica. Heredity, $29,151-175$.

MATHER, K., AND JINKS, J. L. 1971. Biometrical Genelics. Chapman and Hall, London.

PERKINS, J. M., RGLINGTON, E., AND JINKS, J. L. 1971. The nature of the inheritance of permanently induced changes in Nicotiana rustica. Heredity, 27, 441-457.

MOORE, C. A., AND EGLINGTON, E. G. 1973. The nature of permanently induced changes

in Nicotiana rustica. III. $\mathrm{F}_{5}$ generation for five characters. Heredity, 31 , in press. 